\title{
The Role of New Media in Multicultural Australia: A Study of Thai, Rohingya and Hmong Communities
}

\author{
By Natcha Krisneepaiboon *
}

In becoming a part of Australia's multicultural community, members of ethnic minorities need to communicate and stay connected with their friends, family and others in Australia in order to ensure their community cohesion. In the 1990s, mobile devices in turn underwent another major technological innovation-access to the internet. Mobile device users can access the internet much more conveniently than ever before. Communication via mobile devices has become one of the most common ways through which minority people are empowered to sustain and constitute their community connections today. This Higher Degree research mainly focuses on new media use (the mobile internet) amongst Australia's multicultural communities. It aims to better understand the ways in which various ethnic community groups communicate via mobile devices. First, the project explores whether communities are using these technologies to sustain and constitute their community connections and cultures. Secondly, it investigates what broader impact this communication technology is having on minority communities in Australia. Three minority communities - Thai, Rohingya and Hmong - are the subjects of research. The ultimate goal is to find ways to help policymakers to assist ethnic minorities to live their life in a multicultural country like Australia. The project employed a case study methodology as the main research approach which also includes the application of Ethnographic Action Research (EAR). This approach will allow the research questions or issues to be explored more deeply and contextually through the real experiences of the selected community participants and their particular cultural environments.

\section{Introduction}

Smartphone, an emerging affordable new communication technology, has become part of the everyday lives of billions of people around the world. Nowadays, people are not only reliant on mobile devices for voice communications. Other non-voice functions for the mobile devices include receiving and sending images or short videos, interacting video

${ }^{*}$ Student Researcher, Griffith University, Australia. 
communications and being a personal portable computer all of which sometimes overpower the original voice mobile phone practices (Goggin, 2006). These development were due most directly to the evolution of technological breakthroughs and advancement in the means of electronic distribution and handling of information. The productive functions including portability, mobility and customisation of mobile device make themselves fit easily into the way of life of people no matter who or what they are.

The communication technology is also commonly enjoyed by minority people in Australia who are living away from their country of origin as it encourages the capacity for borderlessness. They are able to maintain links with their families and friends back home and also with the communities in the country where they are currently staying.

To bring such telecommunication technology and a cultural study together, this research on smartphone usage by minority people in Australia investigates the ways in which mobile devices help to assist ethnic minorities to sustain and constitute their community connections. The analysis embraces a framework based on Anderson's notion of imagined community (1983) and Habermas's historical concept of the public sphere (1989) frameworks.

Three cultural collectives - Thai, Rohingya and Hmong, were chosen as case studies to stress the central focus of the project which to limited to Asia, the region from where I come (Thailand). Moreover, I was aware of synergies between these and the Thai community to which I belong. My reasonable familiarity with the range of cultural backgrounds, values and practices that the three communities have shared would help me understand, explore and reflect better on the criteria for interpreting the finding. The cohesive nature of the unit of analysis would be more likely to produce meaningful outcomes.

\section{Multicultural Australia}

Australia, an island continent and the world's sixth largest country, is home to a staggering diversity of people who have come from all over the world, for different reasons and in different ways. They include people from influential as well as small, lesser-known countries. These people range from small religious groups living in local communities to large ethnic groups living side-by-side with the majority population. As the Australia Multicultural Council (2011) reports, since the Second World War, more than seven million migrants have settled in Australia. Australia is made up of a majority population from a roughly homogeneous ethnic background and a number of minority populations. According to the 2011 recent Australia census, one in four of 22 million Australians was born overseas. In addition, 44 percent of Australian residents were recorded either as having been born overseas or having at least one parent who was. Moreover, there are more than 260 languages spoken throughout Australia with people identifying with more than 270 ancestries (Department of Immigration and Border Protection, 2011). 
The Australian nation is a product of a unique blend of established traditions and new influences. Integration of people from different countries, ethnic or tribal groups and religions has made this country one of the most ethnically diverse societies in the world (Australian Government, n.d.).

Multiculturalism is a concept and policy which has been formulated to respond to the notion of the recognition of co-existence of a plurality of cultures within the nation (Australian Government, Department of Immigration and Border Protection, 2011). The increasing ethno-cultural diversity of Australian society resulting from mass immigration in the decades following the Second World War has encouraged the Australian government to address immigration and to more actively manage migrants and displaced persons' settlement as well as the public discourse around this process. The term 'multicultural' which has been being frequently used to describe the character of the growing ethno-cultural diversity of society has changed its meaning significantly from time to time. Initially, from the time of Australian federation in 1901 until the latter part of the 20th century, the fundamental attitude to migrant settlement was rooted in the intentional favouring of immigration from certain European countries. This approach was commonly recognized as "The White Australia Policy". The fundamental aspect of the White Australia Policy was the expectation of assimilation (Department of Parliamentary Services, 2010). The government's assimilation policies expected migrants and refugees to assimilate and to rapidly become indistinguishable from the Australia-born population. It was perceived as a means towards building a united Australian nation and preserving the homogeneity of the country.

By the 1960s and 1970s, the ineffectiveness of cultural assimilation was noticeable. Migrants indicated less ability or willingness to assimilate which was accompanied by persistent migrant welfare problems. These issues generated a high level of criticism of the institutional system of migrant settlement (Castles, 1987). A greater awareness of the difficulties encountered by new migrants was visibly recognised and examined. In the mean time, there was an extensively expansion of the recognition of the impressive possibilities if new migrants could integrate fruitfully into the Australian community without leaving their own treasured national identities, values and beliefs behind (Department of Parliamentary Services, 2010). As a consequence, the central point of the government immigration policy significantly changed. The policy of assimilation moved towards a focus on integration. The recognition of a situation of cultural pluralism recognised that the nature of Australian society and culture was changing positively due to the presence of migrants. This changing perception that was broadly developed throughout the nation was a paramount factor that accelerated the abolition of the White Australia policy in 1966.

By 1973, a positive change in appreciation of the ethno-cultural diversity of Australian society was formally and profoundly modelled. The term 'multicultural society' was first presented in a famous speech entitled 'A Multi-Cultural Society for the Future' delivered by the Minister for Immigration under the Whitlam Government, Al Grassby (Lopez, 2000). The 
term was used to highlight that government services and programs must be responsive to the needs of the country's culturally and linguistically diverse communities as the presence of ethnic communities was viewed as an enrichment of Australia (Castles, 1987; Lopez, 2000).

The character of multiculturalism has continually developed. During the Fraser Government of 1975-1983, the policy of multiculturalism was emphasised even more. The development of Australia's multicultural policy was heavily influenced by the 1978 report of Frank Galbally's Committee, Migrant services and programs, ,, generally known as the Galbally Report, which addressed issues with living in and planning for a multicultural Australian society. The report was praised as a vital landmark in the move to multicultural Australia.

Castles (1999) argues that the announcement of the statement of policies and goals placed the essence of multiculturalism at the core of the notion of a multi-ethnic national identity and citizenship. The term 'multiculturalism' has changed its meaning significantly according to how the fundamental idea of national identity is constructed (Stratton \& Ang, 1994). Ethnic minority cultures are now welcomed and celebrated as enriching Australian national culture rather than threatening it. To promote and sustain an inclusive view of Australia, it has become impossible to exclude a consideration of multiculturalism.

Until the present, multiculturalism remains situated at the heart of national policy. A statement written into the Australia's 2011 multicultural policy, The People of Australia (Department of Immigration and Border Protection 2011, p. 2) reads: "Australia's multicultural composition is at the heart of our national identity and is intrinsic to our history and character".

\section{Migration in Australia}

In today's world, the globe seems to be as small as a "global village". There are increasing movements of people, knowledge, ideas and goods across national borders. Migration, the movement of people from an origin to destination, or from a place of birth to another destination across international borders which can recognised as intrinsic features of the globalised world, is a phenomenon growing in scope, complexity and impact which leads to interconnectedness among world's population.

The recent statistic presented by the United Nations (2013) indicated that in 2013, more than 51 percent of all international migrants in the world were residing in just ten countries - the largest number of international migrants stayed in the United States of America. The Russian Federation recorded the second largest number, followed by Germany, while Australia hosted the ninth largest number.

In Australia, according to the latest Australian Census in 2011 (Department of Immigration and Citizenships, 2014), the number of Thai people living in Australia was 45,465 - an increase of almost 48.8 percent 
from the 2006 census. The most recent census also records the estimated number of Thai people distributed throughout the various states and territories. New South Wales had the greatest number of Thai people $(17,541)$, followed by Victoria $(10,766)$, Queensland $(7,022)$ and Western Australia $(5,662)$.

Rohingya, the Muslim ethnic minority, is one of the refugee and asylum seeker communities in Australia. Rohingya people mainly migrate to Australia as refugees as they encounter increasing levels of oppression in their homeland, Myanmar. The number of Rohingyas residing in Australia is difficult to quantify. However, Australia's Department of Immigration and Border Protection (2011) reveals that the majority of stateless maritime arrivals to Australia are from Kurds, Palestinians and Rohingya.

Hmong is one of the Australia's smallest ethnic minorities. There is no official report from the Australian Government indicating the estimated number of Hmong people in Australia. However, Tapp \& Lee (2010) reveal that there are more than 2,000 Hmongs distributed in four of Australia's eastern states. The appearance of Hmong communities in multicultural Australia

has been first recorded in March 1976.

In situations of displacement from beloved landscapes and acquired tastes to an unfamiliar land, there are a number of additional issues and problems migrants encountered apart from prevailing issues affected by mainstream populations. Significant problems may include language proficiency and language barriers, settlement issues, racism and discrimination and employment and education. In order to adjust their new lives to new ways of living and cultural differences in a new homeland, assistance and support from relevant sources are required.

To be able to live in relative harmony with tolerance and acceptance of diverse beliefs, values and practices, newcomers also need to enjoy their own cultural and linguistic practices and be represented based on people's values and perceptions of culture and identity. It is often the experience that migrants including three collective communities, Thai, Rohingya and Hmong, have a very strong sense of belonging and community connectedness. The need to maintain their own culture is considered a predominant necessity of their migration experience. To retrieve what they have missed, people's actions include recreate the atmosphere of their homeland in their new receiving land, strongly maintain their connections with people of the same groups, and find their own places or channels that allow them to be able to enjoy their cultural ways of life (Leung, Lamb \& Emrys 2009). Shavit (2009, p.24) insists that "these efforts were constructive in reducing to some extent yearning feeling and in bridging some of the gaps between individuals and their homelands".

These days in the world of personal computer and internet, communications technologies such as the mobile internet perform important social, cultural and informational roles. Disfranchised, disempowered, local, specialist groups can employ mobile devices as an important tool to establish themselves in a new country and sustain connection with their virtual communities. The need for minorities to find their place in society and to 
connect to those people who have similar backgrounds and interests can be responded to by the use of new media. Communication on mobile devices are also able to create a precious opportunity for cultural identity, language and culture to secure their places in their new country.

\section{Communication Technology (Mobile Telephony)}

Significant changes in the traditional personal communication of people had been signalled since the invention of the telephone in the second half of the 18th century (Goggin, 2006). By the middle of the 20th century, communication between people over telephones was one of the most common ways that people employed to keep their connection with their friends and family, to engage in social activities and also to reach potential customers in business activities. However, not so long after the prevalence of the fixed telephone, the mobile phone has dominated by showing a remarkable rate of adoption throughout the world (Agar, 2003).

One of the foremost factors why mobile phones are now so popular is that mobile communication practices have enhanced individual autonomy in the way in which other kinds of media cannot (Donner, 2009). Mobile phones have a great potential to reduce social exclusion and marginalisation by bringing daily activities more closely to personal and allowing greater participation in the public sphere. Moreover, the advancement of telecommunication technologies affected the way in which people reach information as never before. There has been media transformation which merges media, social and cultural practices across the sectors. The mobile has undergone far beyond just a medium for voice communication. Nowadays, it is normally seen as a hybrid device articulated with other new technologies such as a good quality digital camera, a personal video communication and a portable digital assistant. The convergence of mobile phone with other media, especially the internet, has created new forms of media consumption and culture of uses.

With the help of smartphones, people are able to perform a wide variety of their everyday tasks much more conveniently. Those may include keeping abreast of the latest news, maintaining their connections with people of the same groups, researching products and services and sharing important or interesting messages to others across the globe anywhere and anytime with just a click of a button as long as their mobile reception is available. Therefore, it is not surprising that the mobile phone has been denoted as the future of networked communication (Yuan, 2012).

Discussions of online community in new media studies have observed that online networked communication enriches the intense feeling of solidarity and support (Yuan, 2012). Arguably, the development of online social relationships could be more beneficial with the enjoyment of mobile internet usage as technology is considered as the tool by which marginalised people can speak out about their social and cultural issues. 
In Australia only, the smartphone is a relatively new phenomenon, becoming a substantial part of the habits, preferences and options of Australian residents. There is a Google's Our mobile planet study (2013) investigating smart phone adoption and usage across 48 countries. It showed that Australia ranked the 6th of top 15 countries with the highest smartphone penetration at $64.6 \%$ (see Figure 1).

Figure 1. Australia ranked $6^{\text {th }}$ in Smartphone Penetration in 2013

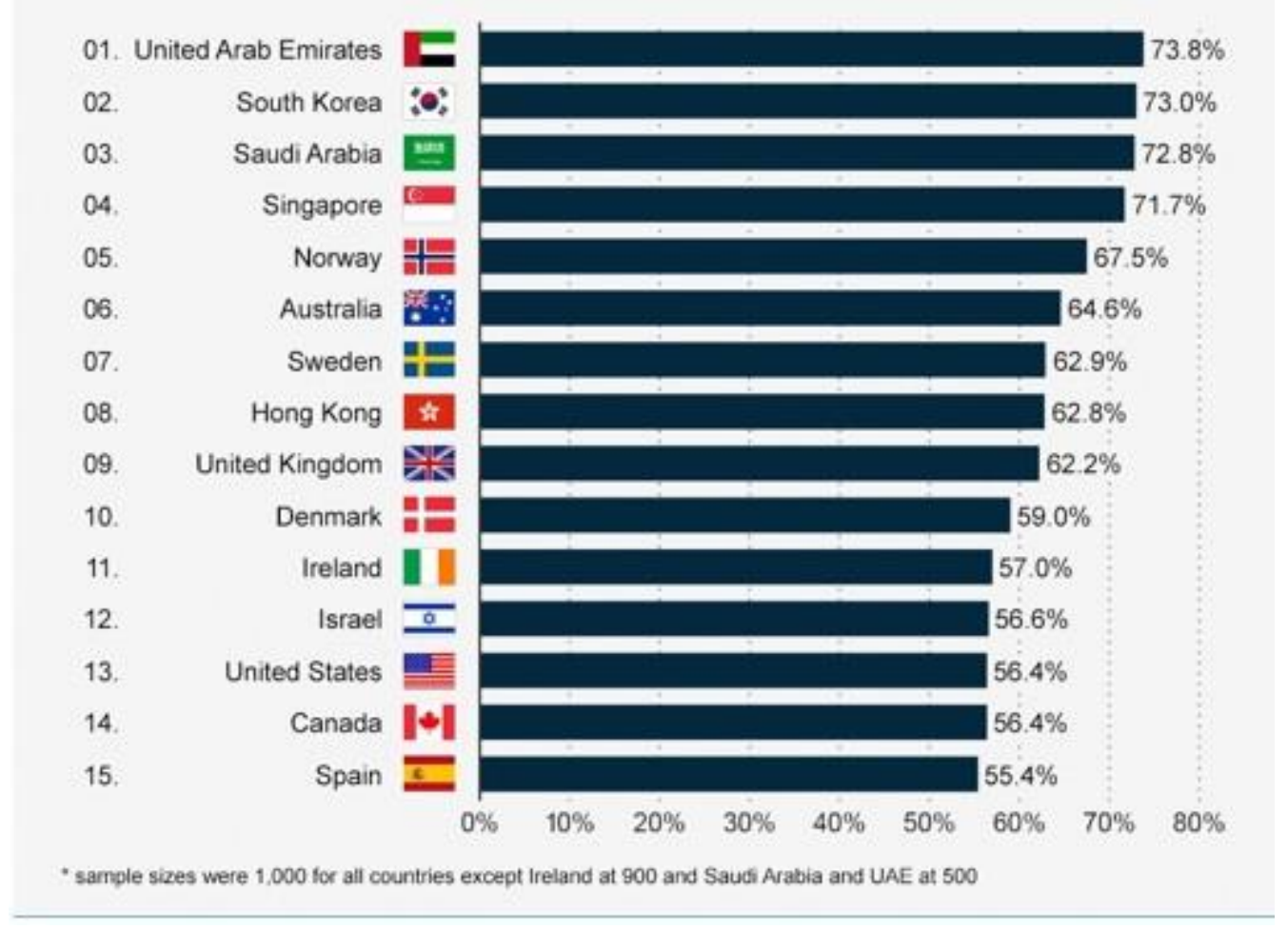

The study (2013) also emphasises the widespread adoption of Australians' smartphone by revealing that 77 percent of Australians never leave home without their handheld companions as they recognise their mobile devices are a multi-activity portal.

\section{Imagined Communities}

The concept of Imagined communities was first published in sociological literature in 1983 (reissued with additional chapters in 1991) in Benedict Anderson's influential book entitled 'Imagined Communities: Reflections on the Origin and Spread of Nationalism'. In this book, Anderson (1983) offers a new important way to look at the nations and nationalism as an imagined political community and to experience community based on indirect social relationship. The very term 'imagined communities' captures Anderson's idea that "all communities larger than primordial villagers of face-to-face contact...are imagined (Anderson, 1983, p.15)". According to him, a nation is a 
collection of people who are living in an area bounded by a border. The border line could be recognised in an enormously scaled-down, two-dimensional representation. These people cannot possibly know each other personally as their relationship is not based on everyday, face-to-face interaction. However, they all believe fervently in the existence of each other; and also have allegiance to a core set of values and beliefs as part of the same nation. In other words, a nation is a socially constructed community, imagined by the people who perceive themselves as part of that group and have always known that they are connected to people they have never seen. An image of affinity becomes the powerful emotional bond that hold people together in an imagined community.

The issue of the personal sense of national identity and belonging is part of the conceptual apparatus required for analysing the idea of imagined communities. In order to spread the sense of nationality, Anderson (1983) considers the spread of publishing in a vernacular language and the gradual demotion of Latin as the prime social conditions help in making the national form of 'imagined communities'. To him, (1983) linguistic is the prime condition of the cultural condition of nationalism. The widespread of vernacular print-language media allow religious communities from all local vernaculars to produce and consume their own local cultures and are no longer integrated by their dependence on a core, Latin-writing print media.

As time passes, not only print media, but also other forms of communication have played an important role in articulating a community imagining. The growth of new communication technologies has made it possible for people to link themselves to others much more conveniently and effectively.

More to the point, the evolution of technological breakthroughs and advancement such as satellites and fibre optic communications as a result of the process of globalisation has created massive global change (Flew, 2002). Digital technology, fibre optics and the internet which developed in the 1990s connect individuals worldwide. The growth of new communication technologies, particularly the internet, has allowed both individuals and businesses to overcome geographical, cultural and logistical barriers. With the help of the internet, people all over the world are able to communicate, traverse and challenge national boundaries and concepts of national identity (Anderson, 1983; Foster, 1991 and Robertson, 1992). At the same time as the internet seems to be erasing boundaries between nations, it is also bringing national diasporas closer together. It may be said that, due to the loss of physical contact, the imagined communities of diasporas over the internet are even stronger, more visual and clearly imagined (Bernal, 2006; Pentecost,2011). The internet helps encourage the imagined community because it facilitates massive dissemination of information that is relevant and important to community building and people's lives. The internet offers opportunities for people to share their own experience about communities to others, to imagine and reconceptualise themselves through email, social networking sites, personal blogs, online publications, podcasts and other forms (Robinson, 2006). It can 
be argued that more than ever, the internet has increased connectivity between people and created complex networks among them by enabling people to think about themselves and relate to others. This electronic revolution has encouraged the variation and democratisation of information as people are able to communicate their opinions, ideas and beliefs about issues of concern, local and global, that affect their everyday lives in a larger world.

The development of communication technologies from time to time has in some ways influenced the process of dissemination of national information, which helps generate the construction of an imagined community. As a consequence, it is not surprising that Anderson (1991) acclaims mass communication is a significant factor holding fabrics of imagined community together (Anderson, 1991). However, in the 1992 article entitled 'The new world disorder' of Anderson, he proposes the other factor, 'mass migrations' as one of the most significant aspects together with mass communication that influentially generate nationalism and construct imagined community. He (1992, p.7) acclaims that "the two most significant factors generating nationalism and ethnicity are both closely linked to the rise of capitalism. They can be described summarily as mass communication and mass migrations".

\section{Media and their Role in the Public Sphere}

The theory of the public sphere is a well-known idea which originated in the 18th century conceptualised by a German philosopher and sociologist, Jurgen Habermas. Habermas (1989) defines the idea of the public sphere as a forum distinct from both state and official economic activity, where individuals can engage and articulate their independent views through communicate collectively on relevant and interested issues, allowing citizens to inform themselves about societal developments and to observe and control political, economic and other elites. Access to this forum was assured to all citizens in society.

Through engagement in the public sphere, an individual human being is seen as making a precious contribution to rational-critical debates with the potential to move discussion from a private to a public environment. The rational public discussion is facilitated as a result of the capacity for people to freely discuss, identify societal problems, and make comments about those particular situations. Habermas (1989) argues that it then promotes the formation of public agreement and decision-making based on public opinion in the strong sense of a consensus about the common good. In addition, the result of the public debate could be encouragingly translated into, and modelled around, state policies of the institutions of society.

In order to spread information to a large public, Habermas insists that media institutions have been required. The media represent a major pillar serving society. The use of public means to facilitate communication among people, along with encouraging them to experience representations of world issues, enriches individual lives. People in society are informed via the process 
of representation, interpretation and evaluation by the media; they know what the world is like and what is happening around them which enables a broader participation and movement in civil societies (O'Shaughnessy \& Stadler, 2002). In other words, the media distribute information as well as facilitate the formation of public opinion and providing an independent forum for debate. Communication through media thus assists the capacity for people to freely discuss, identify societal problems, and make comments about those particular situations. The wide array of information presented in the media can make people change their opinions and views in a positive way. This change is certainly important for the improvement of individuals and the public. It thus seems to be a widely accepted fact that mass media indeed are the public sphere.

In today's world marked by globalisation, media have become the foremost manifestation of the process of connectivity. New information and communication technologies including the internet and surrounding digital transportation and computer networks allow global networks to connect anyone around the world. Communication through media allows both individuals and businesses to overcome geographical, cultural and logistical barriers.

The internet, as a new information and communication technology, is another channel that has played a pivotal role in this process since it was established. The "World Wide Web" (www.) has evolved dramatically over the past two decades. It is arguably the single most important communication breakthrough that has transformed the way people communicate their opinions, ideas and beliefs about issues of concern, local and global. It has become a valuable resource for political and social participation.

With the notable help of new information and communication technologies, the variation and democratisation of information has been encouraged in the new public sphere. Its great ability in overcoming geographic confinements, to shorten distances between people and in bringing people closer together encourages people in the cyber world to regularly connect through a sense of common interests, based on rational and critical thought rather than being limited by cultural stereotypes. The public sphere promoted by cyberspace provides a place where people can communicate and share their opinions and beliefs about particular issues without worrying about differences of background, race, religion, educational level, age and gender. Moreover, online discussions may erase economic inequalities. On this platform, little-known individuals and groups are able to directly connect with citizens and potentially restructure public affairs. That means communication via this virtual space can be more open and free, thus promoting a more enlightened democratic exchange of ideas and opinions. At the same time, a new unbounded online space undoubtedly meets people's needs in terms of information presentation. The online platform plays a decisive role in offering a wide range of political information as well as a huge diversity of media equally for all internet-users to access. People are able to acquire knowledge and political information in a more convenient form and also at the lower cost, 
which could positively result in the improvement of communicative interaction.

\section{Conclusion}

This research critically analyses the role of the mobile internet in serving the needs of ethnic minorities in multicultural Australia. The evidence to date suggests that new media can be used for the needs of maintaining of cultures and languages; creating community connections and networks; and creating a sense of belonging. The role of new media will be further explored in my future continuing research based on the concept of imagined communities by Anderson and the public sphere by Habermas to find out whether communications via mobile internet create and maintain communities of interest among minorities and construct the idea of imagine community. Moreover, the research will answer whether new media facilitates rational and critical communication in the healthy public sphere.

\section{References}

Agar, J. (2003). Constant touch: a global history of the mobile phone, Cambridge: Icon books.

Anderson, B. (1983). Imagined communities: reflections on the origin and spread of nationalism, London: Verso.

Anderson, B. (1991). Imagined communities: reflections on the origin and spread of nationalism. $\left(2^{\text {nd }}\right.$ ed). London: Verso.

Anderson, B. (1992). The new world disorder. New Left Review, 1(193), 3-13. Retrieved from http://newleftreview.org/I/193/benedict-anderson-the-new-worlddisorder.

Australian Government, Australia Multicultural Council. (2011). A multicultural Australia. Retrieved from http://www.amc.gov.au/multicultural-policy.htm.

Australian Government, Department of Immigration and Border Protection. (2011). The people of Australia: Australia's multicultural policy. Retrieved from http:// www.immi.gov.au/media/publications/multicultural/pdf_doc/people-of-australiamulticultural-policy-booklet.pdf.

Australian Government, Department of Immigration and Citizenships. (2014). Community information summary: Thailand born, Retrieved from http://www. immi.gov.au/media/publications/statistics/comm-summ/_pdf/thailand.pdf.

Australian Government. (n.d.), Our country, Retrieved from http://australia.gov.au/ about-australia/our-country.

Bernal, V. (2006). Diaspora, cyberspace and political imagination: the Eritrean diaspora online. Global Networks, 6(2), 161-179. Retrieved from http://www. socsci.uci.edu/ vbernal/bio/Bernal-diaspora.pdf.

Castles, S. (1987). Multiculturalism. New South Wales Parliamentary Library Background paper, Centre for Multicultural studies, University of Wollongong, NSW.

Castles, S. (1999). Challenges to national identity and citizenship: a comparative study of immigration and society in German, France and Australia. Centre for 
Vol. 1, No. $1 \quad$ Krisneepaiboon: The Role of New Media in Multicultural Australia...

Asia Pacific Social Transformation Studies, CAPSTRANS/CEDA Policy papers Series No.1, University of Wollongong, NSW.

Donner, J. (2009). Blurring livelihoods and lives: the social uses of mobile phones and socioeconomic development. Innovations, 4(1), 91-102. Retrieved from http:// research.microsoft.com/pubs/80461/INNOVATIONS-4.1_Donner.pdf.

Flew, T. (2002). New media: an introduction. UK: Oxford University Press.

Foster, R. (1991). Making national cultures in the global ecumene. Annual Review of Anthropology, 20, 235-260. Retrieved from http://www.jstor.org/stable/2155801.

Goggin, G. (2006). Cell Phone culture: mobile technology in everyday life. New York: Routledge.

Google. (2013). Our mobile planet: understanding the mobile consumer, Retrieved from http://think.withgoogle.com/mobileplanet/en/downloads/.

Habermas, J. (1989). The structural transformation of the public sphere: an inquiry into a category of bourgeois society. Translated by $\mathrm{T}$ Burger with the assistance of F Lawrence, Cambridge: MIT Press,

Leung, L., Lamb, C. \& Emrys, L. (2009). Technology's refuge: the use of technology by asylum seekers and refugees. UTS Shopfront Monograph Series, no. 5, Sydney: University of Sydney.

Lopez, M. (2000). The origins of multiculturalism in Australian politics 1945-1975, Victoria: Melbourne University Press.

O'Shaughnessy, M. \& Stadler, J. (2002). Media and society: an introduction. ( $2^{\text {nd }}$ ed). Vitoria: Oxford University Press.

Parliaments of Australia, Department of Parliamentary Services. (2010). Multiculturalism: a review of Australian policy statements and recent debates in Australia and overseas 2010-2011, Research paper no.6, Retrieved from, http://multiculturalsupport.sydneyinstitute.wikispaces.net/file/view/Multiculturali sm\%20\%20A\%20Review\%20of\%20Australian\%20Policy\%20Statements.pdf/20 4903092/Multiculturalism\%20\%20A\%20Review\%20of\%20Australian\%20Policy $\% 20$ Statements.pdf.

Pentecost, K. (2011). Imagined communities in cyberspace. Social Alternatives, 30(2), 44-47, Retrieved from http://www.questia.com/library/journal/1P3-2427804651/ imagined-communities-in-cyberspace.

Robertson, R. (1992). Globalisation, social theory and global culture. London; SAGE.

Robinson, S. (2006). The mission of the j-blog: recapturing journalistic authority online. Journalism: Theory, practice and criticism, 7(1), 65-83. Retrieved from http://jou.sagepub.com/content/7/1/65.full.pdf+html.

Shavit, U. (2009). The new imagined community: global media and the construction of national and Muslim identities of migrants, Academic Press Eastbourne: Sussex.

Stratton, J. \& Ang, I. (1994). Multiculturalism imagined communities: cultural difference and national identity in Australia and the USA. Continuum: Journal of Media and Cultural studies, 8(2), 124-158. doi: 10.1080/10304319409365672.

Tapp, N. \&Lee, G. (2010). The Hmong of Australia: culture and diaspora. $\left(2{ }^{\text {nd }} \mathrm{ed}\right)$. Canberra: The Australia National University.

United Nations. (2013), The number of international migrants worldwide reaches 232 million. Population Facts, no. 2, retrieved from http://esa.un.org/unmigration/ documents/The_number_of_international_migrants.pdf.

Yuan, E. (2012). A culturalist critique of 'online community' in new media studies. New Media and Society, 15(115). doi: 10.1177/1461444812462847. 